\title{
Study of trace elements (Serum Copper and Zinc) in patients of coronary artery diseases
}

\author{
Hiren Sanghani ${ }^{1, *}$, Asha Khubchandani ${ }^{2}$, Sandip Sendhav ${ }^{3}$ \\ ${ }^{1,3}$ Assistant Professor, ${ }^{2}$ Associate Professor, Dept. of Biochemistry, ${ }^{1}$ GMERS Medical College, Gandhinagar, ${ }^{2} \mathrm{~B}$. \\ J. Medical College, Ahmedabad, ${ }^{3}$ M.P. Shah Government Medical College, Jamnagar, Gujarat, India
}

*Corresponding Author:

Email: hirensanghani@gmail.com

\begin{abstract}
Introduction: Previous studies suggest a protective role of the essential trace elements against cardiovascular disease, whereas wistful epidemiological data remains controversial. We aimed to investigate the alteration in concentration of zinc $(\mathrm{Zn})$ and copper $(\mathrm{Cu})$ in patients presented with coronary artery disease.

Materials and Methods: In this case control study 100 normal healthy controls and 100 patients diagnosed with acute coronary artery diseases were enrolled. Serum copper and serum zinc concentration were measured in both the groups.

Results and Observations: Serum copper concentration was significantly higher in patient of acute coronary artery disease (141.0 \pm 15.2$)$ compared to controls $(97.0 \pm 10.8)$. Serum zinc concentration was significantly lower in

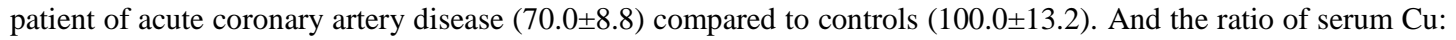
$\mathrm{Zn}$ almost double in patient of acute coronary artery disease patients compared to normal healthy individuals.

Conclusion: From the present study, it is concluded that decreased serum zinc and increased serum copper levels are associated with coronary artery disease. Moreover, results demonstrate that increased serum $\mathrm{Cu}: \mathrm{Zn} \mathrm{ratio} \mathrm{can}$ diagnose occurrence of vascular events even in CAD patients.
\end{abstract}

Keywords: Coronary artery disease, Serum copper, Serum zinc.

Received: $13^{\text {th }}$ July, 2017

\section{Introduction}

Cardiovascular diseases (CVDs), especially coronary heart disease (CHD), have assumed epidemic proportions worldwide. Globally, CVD led to 17.5 million deaths in $2012 .{ }^{1}$ More than $75 \%$ of these deaths occurred in developing countries. In contrast to developed countries, where mortality from CHD is rapidly declining, it is increasing in developing countries. ${ }^{2}$

The risk of coronary artery disease in Indians is higher than White Americans, Chinese, and Japanese. ${ }^{3}$ Indians are prone as a community to coronary artery disease at a much younger age. The disease pattern is severe and diffuse. There is a higher incidence of hospitalization, morbidity and mortality in Indians compare to other ethnic groups. There is a parallel corollary between coronary artery diseasein Indians and the malignant course of rheumatic fever, rheumatic heart disease with associated severe pulmonary hypertension observed by Indian cardiologists in the sixties. In the Western population, incidence of coronary artery diseasein the young is up to $5 \%$ as compared to $12-16 \%$ in Indians. ${ }^{3}$

Increasing prevalence of cardiovascular diseaserisk factors especially dyslipidemia, hypertension, diabetes mellitus, obesity, smoking and sedentary life styles are the major contributing factors for the growing burden of Acute Myocardial Infarction. Along with all these conventional risk factors, few trace elements altered during the disease process of coronary artery disease. All trace elements are essential for human body, but beyond a certain level, they are harmful. Copper is one of the powerful promoters of free radical damage, accelerating lipid peroxidation and causing formation of hydroxyl radicals along with iron. ${ }^{4}$ $\mathrm{Cu}$ and CVD may be associated directly, through a direct effect on the vascular endothelium, or indirectly through lipoprotein metabolism. Copper ions can convert the superoxide and the hydrogen peroxide into the highly harmful hydroxyl radical that can damage to endothelium. ${ }^{5}$ While Zinc acts as a biological antioxidant by a decreasing lipid peroxidation and stabilizing the membrane.Zinc is an important component of biomembranes and an essential cofactor in a variety of enzymes. Zinc has antioxidant-like properties; thus, it can stabilize macromolecules against radical-induced oxidation in vitro as well as limit excess radical production. ${ }^{6}$

In some studies, it was found that trace elements may play a vital role, resulting in either harmful or beneficial effects by damaging or 
protecting vessel wall and altering lipid profile. This study was aimed to know the status and role of serum copper and zinc levels in patients of coronary artery disease.

\section{Materials and Methods}

A cross sectional observational study was carried out at Intensive cardiac care Unit (ICCU) of Civil Hospital, Ahmedabad from July 2011 to February 2012. The study was included 100 patients diagnosed with acute coronary artery disease. Patients were primarily diagnosed by clinical examination, ECG and further evaluated by biochemical investigations. Age and gender matched 100 control participants were selected from the staff working in laboratory department and people coming for their physical fitness without history of any cardio vascular event.
Patients with history of prolonged chest pain, characteristic ECG changes \& increased serum CK-MB level were included in the present study while patients having chronic cardiac disease like, myocarditis, pericarditis, valvular heart disease were excluded from both groups.

Blood samples were collected from all participants in plain tubes without anticoagulants. Serum was separated after centrifugation and stored at $-20^{\circ} \mathrm{C}$. All the serum samples were analyzed for lipid profile, serum copper \& serum zinc level simultaneously to avoid any analytical error. Serum copper \& serum zinc level estimation were done by colorimetric method in ERBA XL640 fully automated Biochemistry analyzer. ${ }^{7,8}$ All data was collected and recorded in excel sheet. All data was analyzed with the SPSS software.

\section{Results \& Observations}

Table 1: Age incidence in Study group

\begin{tabular}{|l|c|c|c|c|}
\hline \multicolumn{1}{|c|}{ Age in Years } & No. of Cases & \% & No. of controls & \% \\
\hline$\leq 40$ Years & 11 & 11 & 14 & 14 \\
\hline 41 to 60 Years & 60 & 60 & 64 & 64 \\
\hline$>$ 60 Years & 29 & 29 & 22 & 22 \\
\hline Total & 100 & 100 & 100 & 100 \\
\hline
\end{tabular}

Table 2: Comparison of Control Group \& Study Group

\begin{tabular}{|l|c|c|c|c|c|c|c|c|}
\hline Parameters & $\begin{array}{l}\text { Biological } \\
\text { Reference } \\
\text { Interval }\end{array}$ & \multicolumn{2}{|c|}{ Control group $(\mathbf{n}=100)$} & \multicolumn{2}{|c|}{ Study group $(\mathbf{n}=100)$} & Significance \\
\cline { 3 - 9 } & & Min & Max & Mean \pm SD & Min & Max & Mean \pm SD & \\
\hline $\begin{array}{l}\text { S. Copper } \\
(\mu \mathrm{g} / \mathrm{dL})\end{array}$ & $80.0-140.0$ & 79.0 & 122.0 & $97.0 \pm 10.8$ & 103.0 & 172.0 & $141.0 \pm 15.2$ & $\begin{array}{c}\mathrm{t}=23.597, \\
* * \mathrm{p}<0.001\end{array}$ \\
\hline $\begin{array}{l}\text { S. Zinc } \\
(\mu \mathrm{g} / \mathrm{dL})\end{array}$ & $60.0-120.0$ & 79.0 & 128.0 & $100.0 \pm 13.2$ & 57.0 & 92.0 & $70.0 \pm 8.8$ & $\begin{array}{c}\mathrm{t}=18.910, \\
* * \mathrm{p}<0.001\end{array}$ \\
\hline
\end{tabular}

Table 3: Comparison of $\mathrm{Cu}$ : $\mathrm{Zn}$ ratio in study \& control Group

\begin{tabular}{|l|c|c|}
\hline \multicolumn{1}{|c|}{ Group } & Serum Cu:Zn (Control group) & Serum Cu:Zn (Study group) \\
\hline Mean & 0.97 & 2.05 \\
\hline Standard Deviation (SD) & 0.16 & 0.34 \\
\hline Sample Size & 100 & 100 \\
\hline Minimum & 0.69 & 1.25 \\
\hline Maximum & 1.5 & 2.64 \\
\hline Significance & $\mathrm{t}=28.74, \mathrm{df}=198, \mathrm{p}<0.001$ \\
\hline
\end{tabular}

In present study, maximum number of patients belongs to 41 to 60 years of age in both groups (Table 1). Serum copper level shows significant increase in study group as compare to normal healthy control group ( $\mathrm{p}<0.001)$ (Table 2). Serum zinc level shows significant decrease in study group as compare to normal healthy control group ( $\mathrm{p}<0.001)$ (Table 2$)$. In present study mean value of serum $\mathrm{Cu}: \mathrm{Zn}$ ratio shows significant increase in study group as compare to normal healthy control group $(\mathrm{p}<0.001)$. (Table 3)

\section{Discussion}

Trace elements are being increasingly recognized as essential mediators for the development and progression of cardiac diseases. On theoretical grounds, trace elements, including copper and zinc found to be protective against 
oxygen free radicals in the development of cardiovascular disease. ${ }^{9}$ It is well established that several trace elements are of great importance in a number of biological processes, mostly through their action as activators or inhibitors of enzymatic reactions, by competing with other elements and proteins for binding sites, by influencing the permeability of cell membranes, or through other mechanisms. It is therefore reasonable to assume that these minerals would also exert an action, either directly or indirectly, on the cardiac cell, on the blood vessel walls, on the blood-pressure-regulating centres, or on other systems related to cardiovascular function such as, e.g. the lipid and carbohydrate metabolism. ${ }^{10}$

In present study mean serum copper level shows significant rise in coronary artery disease patients compared to normal healthy control participants. In present study, serum copper level increases in patients with coronary artery disease and it coincides well with studies by Ramesh et $\mathrm{al},{ }^{4}$ Ramakrishnan et $\mathrm{al},{ }^{9}$ Nourmohammadi et $\mathrm{al}^{11}$ and Jubaira et al. ${ }^{12}$ Copper is an essential trace element as an important constituent of certain metalloenzymes and protein. Copper is an essential micronutrient for group of enzymes that catalyzes oxidation reduction reaction like, tyrosinase, cytochrome-oxidase, ascorbic acid oxidase, monoamine-oxidase, galactose oxidase and uricase. Oxidation is now thought to play an important role in the pathogenesis of CAD through oxidation of LDL-C and free radical formation and it has been suggested that the oxidation of LDL-C increases atherogenecity. ${ }^{12}$ Elevated copper concentrations may be related to coronary heart disease in at least two ways. Oxidation and free radical formation are two components of atherogenesis. Copper oxidizes low-density lipoprotein cholesterol, increasing its atherogenecity. ${ }^{13}$ Alternatively, copper may be a risk marker for inflammation rather than a risk factor for coronary heart disease directly involved in the pathogenesis of atherosclerosis. ${ }^{14}$ Increased patient's serum copper levels are a part of a specific defense mechanism to provide more copper at the site of infarction to reduce its size and the extent of damage. In addition, the increase of ceruloplasmin, which is a copper containing enzyme and acute phase reactant, may account for the significant increase in serum copper levels. Ceruloplasmin is an acute phase protein and is synthesized by the liver in response to tissue damage and inflammation. Ceruloplasmin is an important intravascular antioxidant and it protects tunica intima against free radical injury. This phenomenon is the basis for constantly observed sudden increase in serum copper and ceruloplasmin levels. ${ }^{15}$
In present study serum zinc level was found significantly decreased in study group compared to control group. The same was observed by previous studies done by Ramesh et al, ${ }^{4}$ Ramakrishnan et $\mathrm{al}^{9}{ }^{9}$ Nourmohammadi et $\mathrm{al}^{11}$ and Shekokar et al. ${ }^{16}$ Zinc is involved in many enzymatic reactions, cellular signaling mechanisms, and other essential functions in the cell. Moreover, although it is not an antioxidant itself, zinc can exhibit antioxidant effects indirectly through the activation of other molecules. Low zinc levels are associated with less comprised antioxidant defenses that normally protect the heart, leading to a susceptibility to oxidative stress. Zinc deficiency is also associated with cell death (apoptosis) in heart tissues, as zinc normally suppresses apoptosis. ${ }^{17}$ Besides that, low serum $\mathrm{Zn}$ levels in patients have been related to excess release of steroids due to the release of leukocyte endogenous mediators which redistribute the body $\mathrm{Zn}$ from serum and may cause a drop in serum $\mathrm{Zn}$ and also due to elevated levels of $\alpha 2$ macroglobulin which is a transport protein containing large amounts of $\mathrm{Zn} .{ }^{18}$

Induction of metallothionein by zinc has been shown to alter the physiological disposition of copper and metallothionein has a greater binding capacity for copper than for zinc, so causing elevation of serum copper level and lowering serum zinc levels. ${ }^{11}$

\section{Conclusion}

From the present study, it is concluded that decrease serum zinc and increased serum copper levels are associated with coronary artery disease. Moreover, results demonstrate that increased serum $\mathrm{Cu}: \mathrm{Zn}$ ratio can diagnose occurrence of vascular events in CAD patients.

\section{References}

1. World Health Organization. Global Status Report on Non-Communicable Diseases 2014. World Health Organization, Geneva, Switzerland;2014

2. Kelly BB, Fuster V, editors. Promoting cardiovascular health in the developing world: a critical challenge to achieve global health. National Academies Press; 2010 Jul 29.

3. Rissam HS, Kishore S, Trehan N. Coronary artery disease in young Indians - the missing link. J Indian AcadClin Med. $2001 \mathrm{Jul}$;2(3):128-31.

4. Ramesh MJ, Kulkarni DG. Evaluation of Effect Of Trace Elements And Antioxidants Levels In Patient With Ischaemic Heart. International Journal of Biotechnology and Biochemistry. 2016;12(2):145-51.

5. Alissa EM, Bahjri SM, Ahmed WH, Al-ama N, Ferns GA. Trace element status in Saudi patients 
with established atherosclerosis. Journal of Trace Elements in Medicine and Biology. $2006 \mathrm{Jul}$ $12 ; 20(2): 105-14$

6. Soinio M, Marniemi J, Laakso M, Pyörälä K, Lehto S, Rönnemaa T. Serum zinc level and coronary heart disease events in patients with type 2 diabetes. Diabetes care. $2007 \mathrm{Mar}$ 1;30(3):523-8.

7. Abe A, Yamashita S, Noma A. Sensitive, direct colorimetric assay for copper in serum. Clin Chem. 1989;35(4):552-4.

8. Tetsuo-Makino. Colorimetric determination of zinc. ChimicaClinicaActa. 1991; 197: 209-20.

9. Ramakrishnan V,Thiyagarajan G, Pulavendran S et al. Study of serum metals and antioxidant enzymes in patients with coronary artery disease. International Journal of Genetic Engineering and Biotechnology. 2010;1(3):205-16

10. Masironi R. Trace elements and cardiovascular diseases. Bulletin of the World Health Organization. 1969;40(2):305.

11. Nourmohammadi I, Nazem N, Ehsani-Zenuz A, Moaveni A. Serum Levels of $\mathrm{Zn}, \mathrm{Cu}, \mathrm{Cr}$ and $\mathrm{Ni}$ in Iranian Subjects with Atherosclerosis. Archives of Iranian Medicine. 2001 Jan;4(1):22.

12. Jubaira S, Mollah FH, Mehdi T, Arslan MI. Serum Copper with Coronary Artery Disease in Male and its Relation with Lipid Profile. Bangladesh Journal of Physiology and Pharmacology. 2008;24(1):7-9.

13. Heinecke JW, Rosen H, Chait A. Iron and copper promote modification of low density lipoprotein by human arterial smooth muscle cells in culture. Journal of Clinical Investigation. 1984 Nov;74(5):1890.

14. Ford ES. Serum copper concentration and coronary heart disease among US adults. American journal of epidemiology. 2000 Jun 15;151(12):1182-8.

15. Abdelhalim MA, Moussa SA, AL-Mohy YH. Heavy and trace elements are important diagnostic tools during the of atherosclerosis; high cholesterol diet supplemented with high zinc level delays or prevents the progression of atherosclerosis. Life Science Journal. 2013;10(4).

16. Shekokar PP, Kaundinya SD. Effect of acute myocardial infarction on serum zinc level. Indian J Basic Appl Med Res. 2013;3:80-7.

17. Merza WM, Majid AY, Rasheed MK et al.Relation of serum zinc and copper level with major risk factor, thrombolysis and echocardiography inischemia.Int J ResPharm Chem. 2016. 6(2), 262-70.

18. Nazem N, Ehsani-Zenuz A, Moaveni A. Serum Levels of $\mathrm{Zn}, \mathrm{Cu}, \mathrm{Cr}$ and $\mathrm{Ni}$ in Iranian Subjects with Atherosclerosis. Archives of Iranian Medicine. 2001 Jan;4(1):22. 